\title{
Fabrication of Microcrystalline Cellulose Incorporated Polyethersulfone Hybrid Mixed Matrix Membrane for Humic Acid Removal
}

\author{
Amirul Islah Nazri, ${ }^{1}$ Abdul Latif Ahmad ${ }^{1 *}$ and Mohd Hazwan Hussin ${ }^{2}$ \\ ${ }^{1}$ School of Chemical Engineering, Universiti Sains Malaysia, \\ Engineering Campus, 14300 Nibong Tebal, Pulau Pinang, Malaysia \\ ${ }^{2}$ School of Chemical Sciences, Universiti Sains Malaysia, \\ 11800 USM Pulau Pinang, Malaysia \\ *Corresponding author: chlatif@usm.my
}

Published online: 25 December 2019

To cite this article: Nazri, A. I., Ahmad, A. L. \& Hussin, M. H. (2019). Fabrication of microcrystalline cellulose incorporated polyethersulfone hybrid mixed matrix membrane for humic acid removal. J. Phys. Sci., 30(Supp. 2), 41-53, https://doi.org/10.21315/ jps2019.30.s2.4

To link to this article: https://doi.org/10.21315/jps2019.30.s2.4

\begin{abstract}
In this study, a combination of blending and dry-wet phase inversion method was used to fabricate hybrid mixed matrix membranes (MMMs) by incorporating different combinations of materials between microcrystalline cellulose (MCC) and lithium chloride ( $\mathrm{LiCl}$ ) for treating feed solution containing humic acid (HA). The fabricated membranes were characterised by scanning electron microscope (SEM), Fourier transform infrared (FTIR) and contact angle (CA) analyses. The membrane performances were subsequently tested for pure water flux (PWF), HA rejection and antifouling behaviour using $50 \mathrm{mg} \mathrm{l}^{-1} \mathrm{HA}$ solution at $\mathrm{pH}$ 7.7. The best MMM was attained when incorporating polyethersulfone (PES) with MCC in the presence of $\mathrm{LiCl}$. In this case, the PWF and permeate flux were significantly increased from $0.5091 \mathrm{~kg} \mathrm{~m}^{-2} \mathrm{~h}^{-1}$ to $11.2990 \mathrm{~kg} \mathrm{~m}^{-2} \mathrm{~h}^{-1}$, and from $0.2066 \mathrm{~kg} \mathrm{~m}^{-2} h^{-1}$ to $7.4330 \mathrm{~kg} \mathrm{~m}^{-2} \mathrm{~h}^{-1}$, respectively whilst maintaining high $\mathrm{HA}$ rejection of $94.91 \%$. Furthermore, the membrane showed excellent antifouling capabilities due to the significant enhancement of the hydrophilicity of the membrane surface resulted from the partial dissolution of MCC in the LiCl/DMAc system. This work demonstrates that modifying PES with MCC in the presence of LiCl can be an effective approach to enhance $M C C$ deposition, physical properties and simultaneously boost the performance of PES membranes for wastewater applications.
\end{abstract}

Keywords: Microcrystalline cellulose, polyethersulfone, lithium chloride, mixed matrix membrane, humic acid 


\section{INTRODUCTION}

Surface water can be defined as water collects on the ground or in a stream such as rivers, lakes, reservoirs and oceans. The main uses include as drinking water and other public uses, cooling down industrial thermoelectric power equipment, and growing agricultural crops. ${ }^{1}$ Nowadays, industries are growing fast to cope with the market demands. These growths, together with the improper industrialisation practices lead to the pollution of the surface water. Natural organic matter (NOM), a heterogeneous mixture of particulate and soluble components of both inorganic and organic matter, is one of the main contaminants found in natural surface water. It can react with free chlorine and produce disinfection-by-products (DBPs) which are carcinogens. Direct exposure may lead to cancers and miscarriages. ${ }^{1}$ Besides that, humic acid (HA) contributes to more than $50 \%$ of the NOM composition. HA is identified as major foulant in membrane water filtration due to their adsorptive capacity on the hydrophobic membrane surfaces which then results in irreversible membrane fouling during filtration. ${ }^{2}$

Membrane separation processes are continuously gaining popularity due to their high selectivity, simple instrument structure, and low running investment. ${ }^{3}$ Polyethersulfone (PES) is one of many polymers used in membrane filtration. It has excellent chemical, mechanical and thermal strength. Due to the excellent properties, it can be operated in a variety of $\mathrm{pH}$ conditions and withstand harsh chemical cleaning. Despite the excellent properties, PES membranes are prone to fouling due to its hydrophobic nature. ${ }^{4}$ This will increase the operating cost of the membranes. Different modification techniques were reported to improve the hydrophilicity of polymeric membranes. ${ }^{5}$ Among those techniques, blending inorganic/organic materials in the membrane matrix is widely used due to convenient operation and mild conditions. ${ }^{5}$ In some cases, blending may suffer problems such as nanomaterials leaching during membrane fabrication/filtration process and aggregation/agglomeration of nanomaterials on the membrane surface which may negatively affect the morphology and performance of the resulted membranes. ${ }^{4,5}$ Therefore, proper dispersion of these particles in the polymer matrix of membrane is of great importance.

Microcrystalline cellulose (MCC) is a promising material to be used in membrane technology. It is renewable, environmentally friendly and non-toxic materials with high biocompatibility. On top of that, it possesses abundant of hydroxyl groups $(\mathrm{O}-\mathrm{H})$ which is expected to improve the hydrophilicity of PES membranes. ${ }^{6}$ Moreover, MCC contains crystalline structure which will further improve the mechanical strength of the membranes. ${ }^{6}$ Despite the benefits, MCC tends to form strong hydrogen bonds with the cellulose chain instead of PES, thus may lead 
to leaching. Zhang has studied the dissolution of cellobiose using DMAc-LiCl system and found that the solvent system successfully mediated the dissolution of cellobiose. ${ }^{7}$ In this study, PES MMMs incorporated with MCC and/or $\mathrm{LiCl}$ via blending for HA removal were fabricated. The fabricated membranes were characterised using scanning electron microscope(SEM), Fourier transform infrared (FTIR) spectroscopy and contact angle (CA). Consequently, the performance of the fabricated membranes including permeability test, HA rejection, and the antifouling property was analysed using cross-flow filtration unit.

\section{EXPERIMENTAL}

\subsection{Materials}

PES Ultrason E6020P with Mw 58,000 $\mathrm{g} \mathrm{mol}^{-1}$ was purchased from BASF. MCC (particle size $20 \mu \mathrm{m})$, HA (technical grade), and sodium hydroxide $(\mathrm{NaOH})$ were purchased from Sigma Aldrich, United States. Lithium chloride (LiCl, ACS Reag., $\mathrm{Ph}$ Eur.) and N,N-dimethylacetamide (DMAc, extra pure) was purchased by Merck and ACROS Organics, respectively.

\subsection{Membrane Preparation}

PES MMMs were synthesised using a combination of blending and dry-wet phase inversion methods. Four membranes were fabricated using different combinations of materials in dope compositions, as parameter studied, such that S0, S1, S2 and S3 consisting of PES, PES with LiCl, PES with MCC, and PES with both MCC and $\mathrm{LiCl}$, respectively. The composition and preparation steps for dope solution are shown in Table 1 and Figure 1, respectively. To remove air bubbles, all dope solutions were degassed for $1 \mathrm{~h}$ prior to membrane casting. Subsequently, the dope solutions were cast on a glass plate using a film applicator with $200 \mu \mathrm{m}$ gap, exposed to air for $45 \mathrm{~s}$, and immersed in a water coagulation bath for $24 \mathrm{~h}$. Finally, the membranes were rinsed with running water and stored in distilled water (DW) prior to usage.

Table 1: Composition of dope solution for membrane preparation.

\begin{tabular}{ccccc}
\hline Membrane & PES (wt\%) & MCC (wt\%) & LiCl (wt\%) & DMAc (wt \%) \\
\hline S0 & 17.25 & 0.00 & 0.00 & 82.75 \\
S1 & & 0.00 & 6.62 & 76.13 \\
S2 & & 0.50 & 0.00 & 82.25 \\
S3 & & 0.50 & 6.58 & 75.67 \\
\hline
\end{tabular}




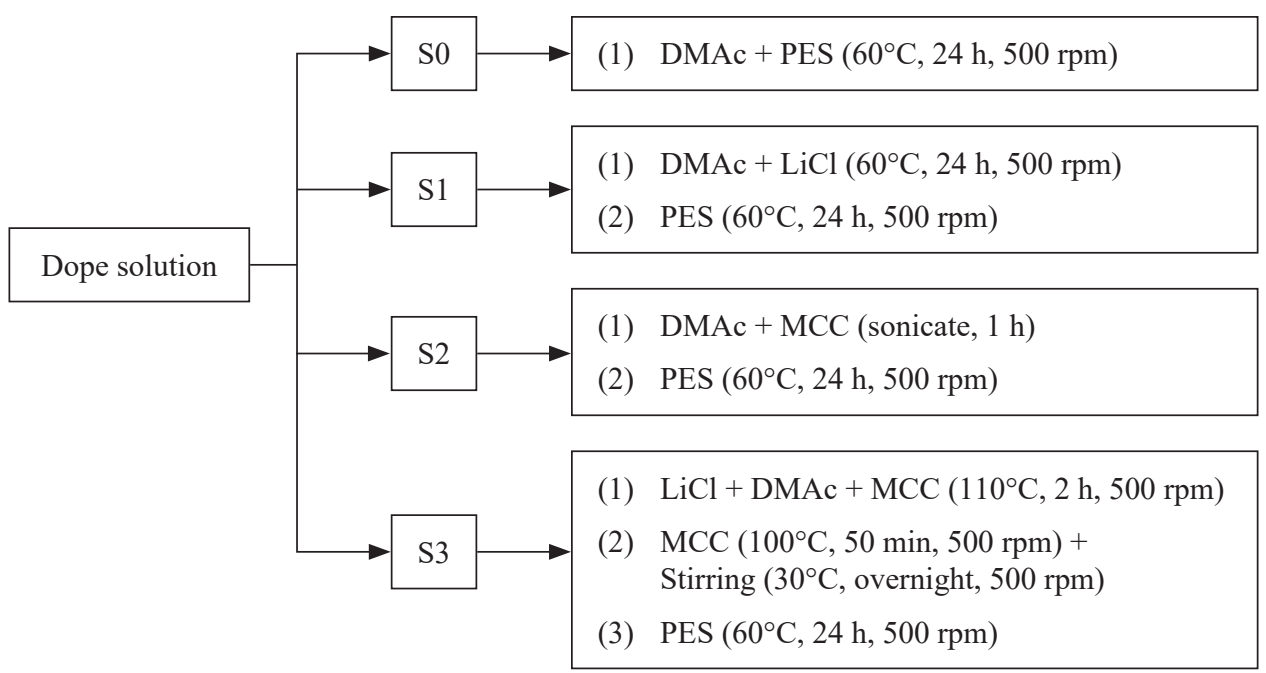

Figure 1: Preparation steps of dope solutions.

\subsection{Membrane Characterisation}

\subsubsection{Cross-sectional and outer surface morphologies}

The observation of the surface and cross-sectional morphology of the membranes were carried out using scanning electron microscope (SEM) (Hitachi Tabletop TM3000). Sputter coater (Quorum SC7620) was used to coat membrane samples with thin layer of gold/palladium for $90 \mathrm{~s}$. For cross-sectional morphology, membranes were cracked with the aid of liquid nitrogen.

\subsubsection{Surface chemistry}

Functional groups and chemical bonding present on samples tested were determined using FTIR (Thermo Scientific Nicolet Nexus 670). All samples were scanned over the wavenumber range from $650 \mathrm{~cm}^{-1}$ to $4000 \mathrm{~cm}^{-1}$ using OMNI diamond accessory.

\subsubsection{Water CA}

Surface hydrophilicity of membranes was determined via CA measurement using goniometer (Rame Hart 250-F1, USA). The membrane was mounted horizontally on a glass slide and $10 \mu \mathrm{l}$ of deionised water (DI) was dropped onto the membrane surface through a needle tip. A magnified image of the water droplet was observed by a digital camera and the average $\mathrm{CA}$ readings of 5 different locations were obtained. 


\subsection{Performance Evaluation of Membranes}

\subsubsection{Membranes filtration test}

Filtration test was run using $50 \mathrm{mg} \mathrm{l}^{-1}$ of HA solution prepared by dissolving $0.05 \mathrm{~g}$ of HA in $11 \mathrm{of} \mathrm{DW}$. The mixture was sonicated for $1 \mathrm{~h}$ and stirred for $24 \mathrm{~h}$ prior to use. ${ }^{4}$ To aid the HA dissolution, the $\mathrm{pH}$ was kept around 7.7 by adding drops of $1.0 \mathrm{M} \mathrm{NaOH}$ into the HA solution. ${ }^{1}$

The procedure for membrane filtration test is shown in Figure 2 and the test was carried out using cross-flow filtration unit as shown in Figure 3. The volumetric flowrate of the feed solution was maintained at $400 \mathrm{ml} \mathrm{min}^{-1}$ unless stated otherwise. The permeation flux of pure water $\left(\mathrm{J}_{\mathrm{PWF} 1}\right)$ was calculated using Equation 1:

$$
\mathrm{J}=\mathrm{V} /\left(\mathrm{A}_{\mathrm{m}}\right) \Delta \mathrm{t}
$$

where $J$ is permeation flux $\left(\mathrm{kg} \mathrm{m}^{-2} \mathrm{~h}^{-1}\right), \mathrm{V}$ is volume of permeate (1), $A_{m}$ is the effective area of filtration $\left(\mathrm{m}^{2}\right)$, and $\Delta \mathrm{t}$ is time (h). Subsequently, the HA concentration in feed and permeate at the end of the experiment was measured using UV-Vis spectrophotometer (UV-Vis Cary 60) at $254 \mathrm{~nm}$. The HA rejection of all membranes was determined using Equation 2:

$$
\text { Rejection }(\%)=\left(1-\left(\mathrm{C}_{\text {permeate }} / \mathrm{C}_{\text {feed }}\right)\right) \times 100
$$

where $\mathrm{C}_{\text {feed }}$ and $\mathrm{C}_{\text {permeate }}$ refer to HA concentration in feed and permeate, respectively whereas the flux of HA filtration $\left(\mathrm{J}_{\mathrm{HA}}\right)$ and pure water flux after membrane cleaning $\left(\mathrm{J}_{\mathrm{PWF} 2}\right)$ were calculated using Equation 1.

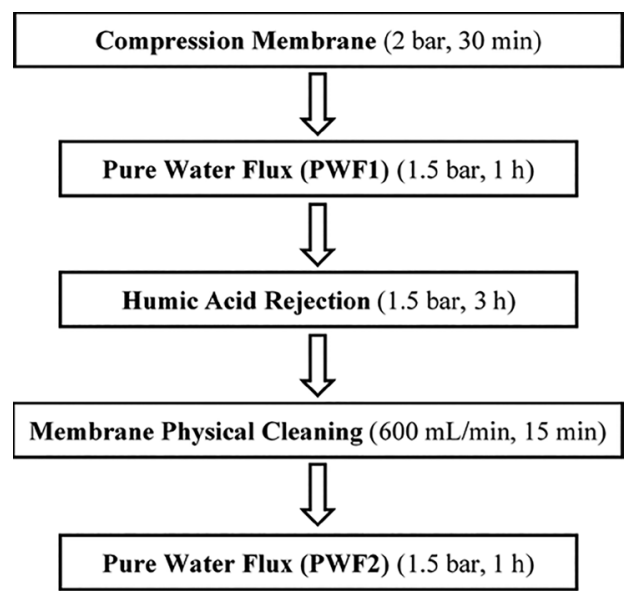

Figure 2: Procedure for membrane filtration test. 


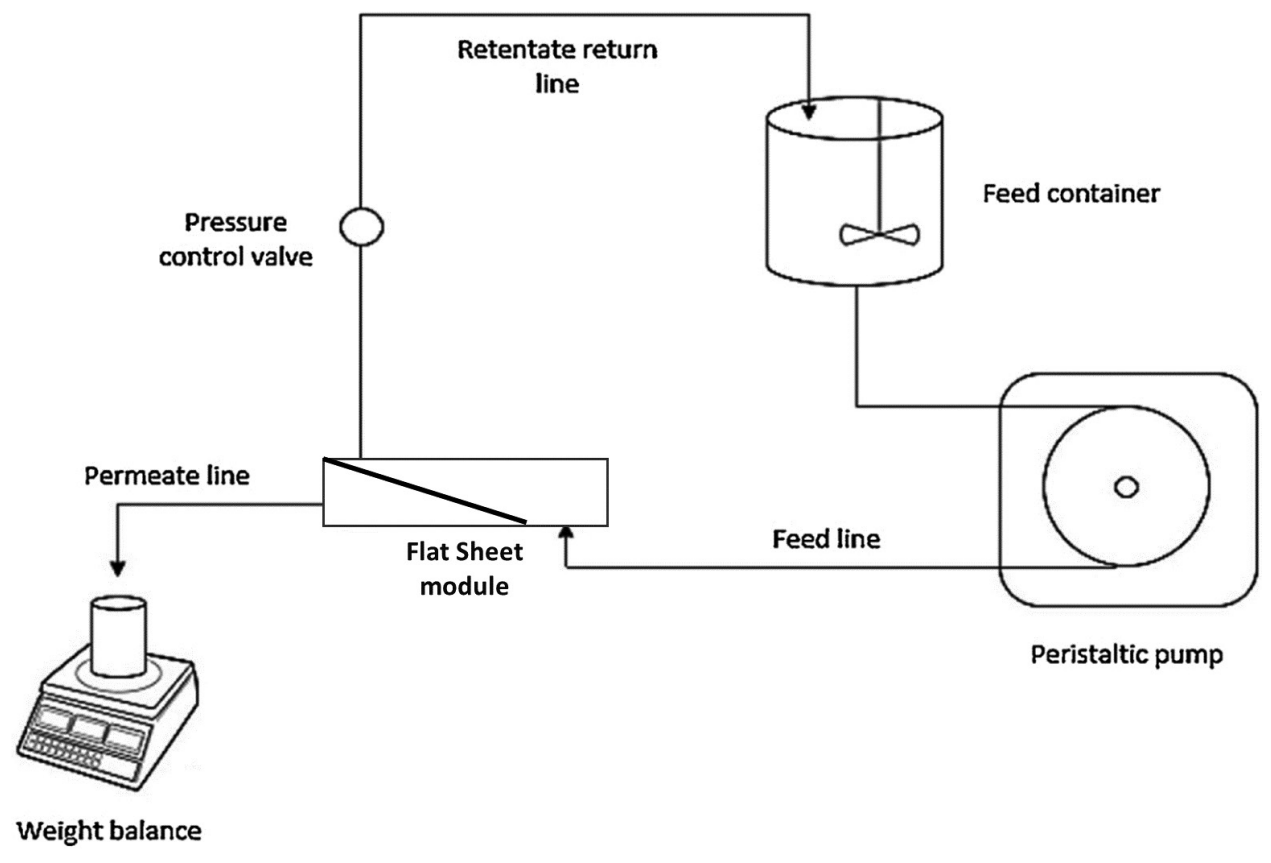

Figure 3: Schematic diagram of cross-flow filtration test rig, adapted from Ahmad et al. ${ }^{4}$

\subsubsection{Fouling evaluation of membranes}

The membranes antifouling capability was determined by evaluating flux reduction and flux recovery after completing one cycle of the filtration. The relative flux reduction (RFR) and flux recovery ratio (FRR) are evaluated using Equations 3 and 4 , respectively.

$$
\begin{aligned}
& \operatorname{RFR}(\%)=\left(1-\left(\mathrm{J}_{\mathrm{HA}} / \mathrm{J}_{\mathrm{PWF1}}\right)\right) \times 100 \\
& \operatorname{FRR}(\%)=\left(\mathrm{J}_{\mathrm{PWF} 2} / \mathrm{J}_{\mathrm{PWF} 1}\right) \times 100
\end{aligned}
$$

\section{RESULTS AND DISCUSSION}

\subsection{Membrane Morphology}

The top surface and cross-section morphology of membranes were determined using SEM and the images are presented in Figure 4. The cross-sectional images show all membranes possess asymmetric pore structures, i.e., top thin layer, middle finger-like structure, and bottom macrovoids pores. $\mathrm{LiCl}$ significantly affects the 
pore structure of $\mathrm{S} 1$ as the finger-like structure becomes longer and macrovoids becomes bigger and wider. Also, the pores on top surface are bigger than the membranes without $\mathrm{LiCl}$, i.e., $\mathrm{S} 0$ and $\mathrm{S} 2$. In this case, $\mathrm{LiCl}$ acts as pore former during membrane fabrication leading to more and bigger pore formation on the membranes. ${ }^{8}$ Meanwhile, no significant changes were observed on S2 morphology due to potential MCC leaching.

(a)
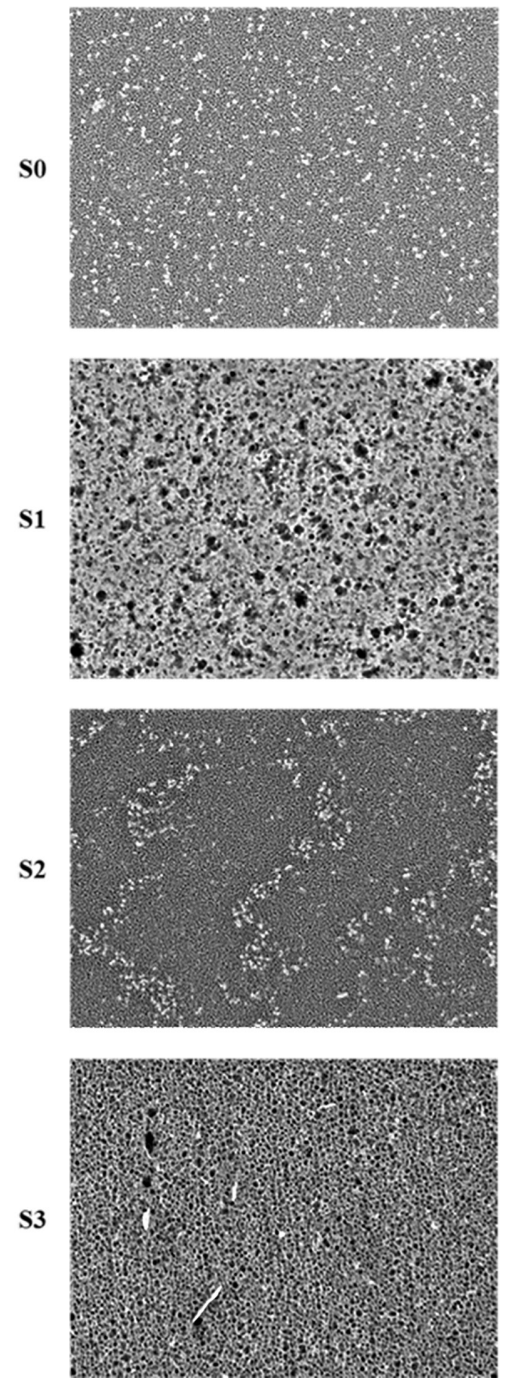

(b)
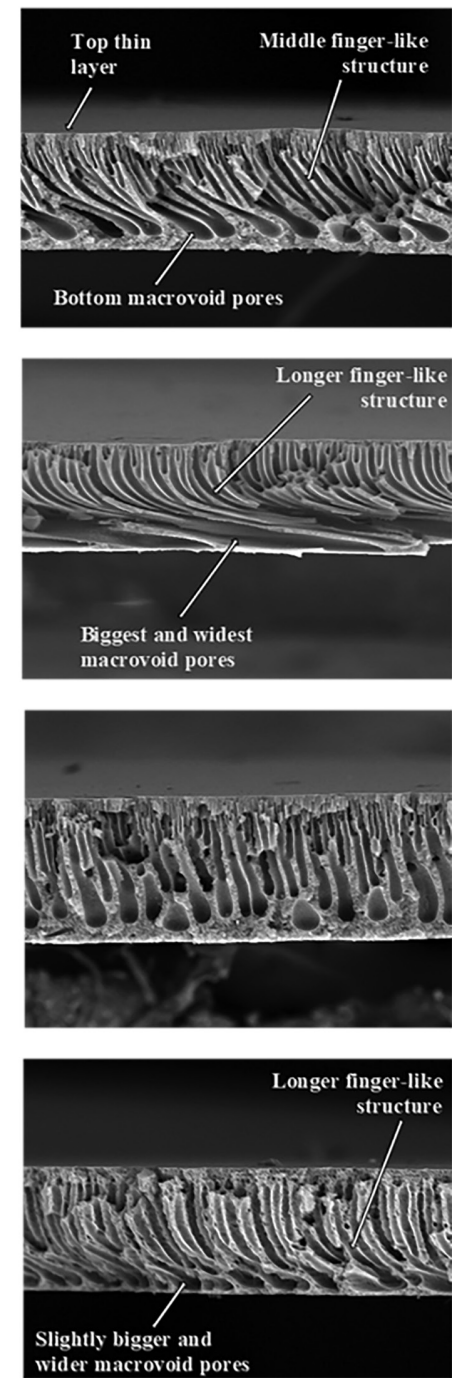

Figure 4: SEM image of membranes of (a) top surface (magnification 1000X), (b) crosssection (magnification 1000X). 
The cross-sectional image of S3 shows longer finger-like structure and slightly bigger macrovoids compared to S0 and S2 but smaller than S1. Also, the pores on top surface show the same behaviours. In addition, the pores on spongelike structure across the membrane are bigger than the rest. These changes in morphology are possible due to several factors acting together on the membrane such as gravitational stretching, MCC dissolution degree, dope formulation and $\mathrm{LiCl}$ incorporation. ${ }^{8}$

\subsection{Surface Chemistry of Membranes}

Figure 5(a) shows FTIR spectra for MCC powder and the as-prepared membranes. The spectrum of MCC shows a similar trend of characteristic peaks with what is being reported in other literature. ${ }^{9}$ The presence of wide peak approximately at $3300 \mathrm{~cm}^{-1}$ and a peak approximately at $1600 \mathrm{~cm}^{-1}$ correspond to the stretching and bending vibrations of hydroxyl groups $(\mathrm{O}-\mathrm{H})$ whereas the peaks approximately at $2900 \mathrm{~cm}^{-1}, 1426 \mathrm{~cm}^{-1}, 1063 \mathrm{~cm}^{-1}$ and $892 \mathrm{~cm}^{-1}$ are attributed to asymmetrically $\mathrm{C}-\mathrm{H}$ and $-\mathrm{CH}_{2}$ stretching vibrations, the pyranose ring ether band of cellulose and cellulosic $\beta$-glycosidic linkages, respectively.

The membrane spectra show S1 and S2 share similar characteristic peaks as S0. This indicates that no additional bonds were made with them as pore former $\mathrm{LiCl}$ and MCC were leached out during coagulation process, respectively. The leaching of MCC related to MCC cannot properly dissolute into DMAc. ${ }^{7}$

S3 spectrum in Figure 5(b) shows new adsorption peak at approximately $3400 \mathrm{~cm}^{-1}$ which corresponds to the $\mathrm{O}-\mathrm{H}$ stretching which indicates MCC were successfully attached on the PES membrane. In the presence of $\mathrm{LiCl}, \mathrm{MCC}$ are partially dissolute and forms hydrogen bond with PES. ${ }^{7}$ The O-H in adsorbed MCC are responsible for the improvement of membrane hydrophilicity and anti-fouling capability.

\subsection{Surface Hydrophilicity of Membranes}

As shown in Figure 6, the average CA for S0 is $67.28^{\circ}$ whereas all modified membranes show a lower CA. The lower CA of $\mathrm{S} 1$ is associated with the bigger pore size due to the presence of pore former in the dope solution whereas the lower $\mathrm{CA}$ of $\mathrm{S} 2$ is due to the presence of the small amount of $\mathrm{O}-\mathrm{H}$ groups from the unleached MCC on the membrane surface. Meanwhile, S3 shows the best hydrophilicity property by having the lowest CA value of $52.95^{\circ}$. The synergistic effect of $\mathrm{MCC}$ and $\mathrm{LiCl}$ induced $\mathrm{MCC}$ incorporation on $\mathrm{S} 3$ surface, thus improving its hydrophilicity and attracts water towards its surface. 


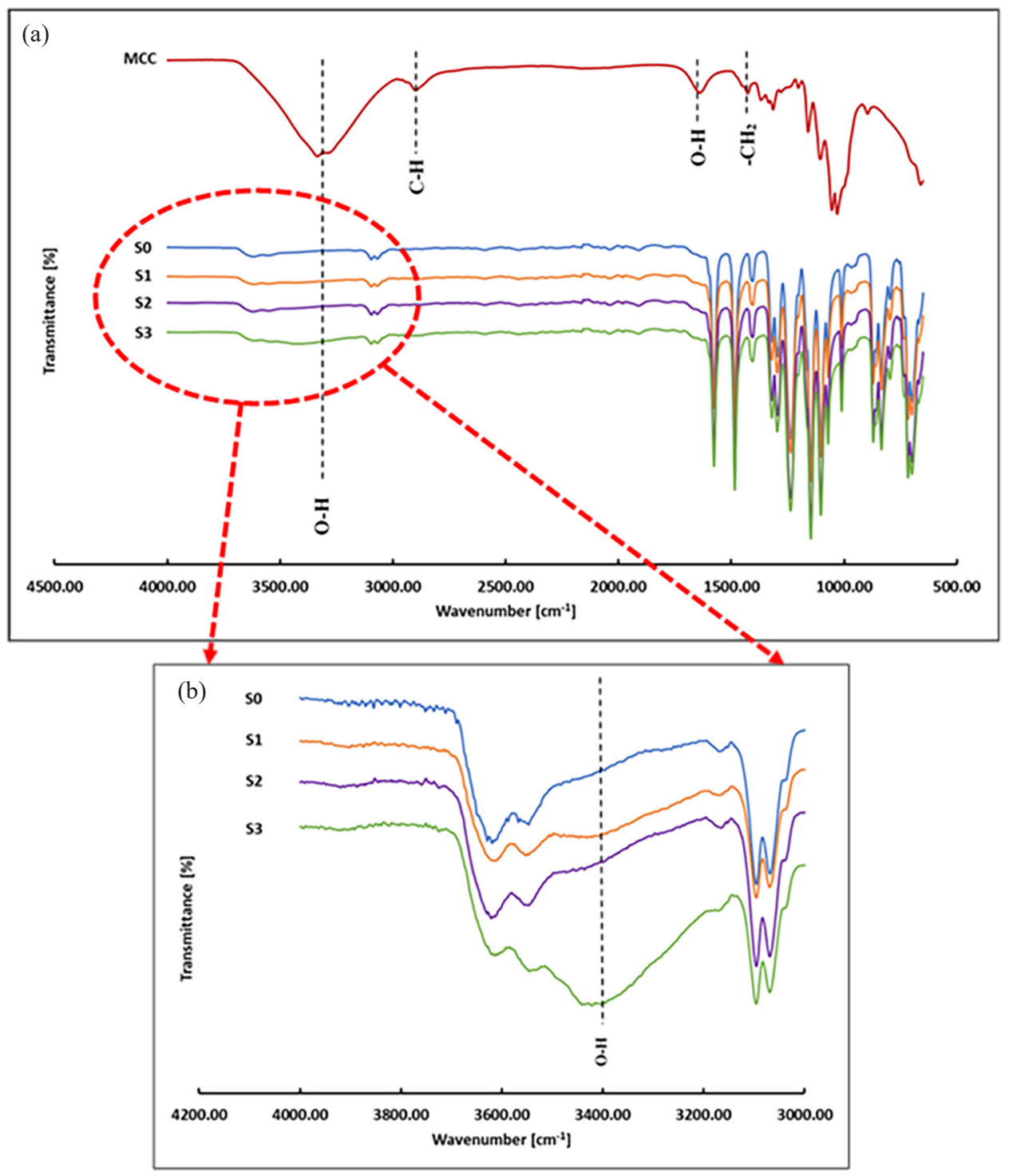

Figure 5: FTIR spectra of (a) MCC powder and S0, S1, S2, and S3 membranes with (b) focused image of the spectra from wavenumber $3000 \mathrm{~cm}^{-1}$ to $4000 \mathrm{~cm}^{-1}$. 


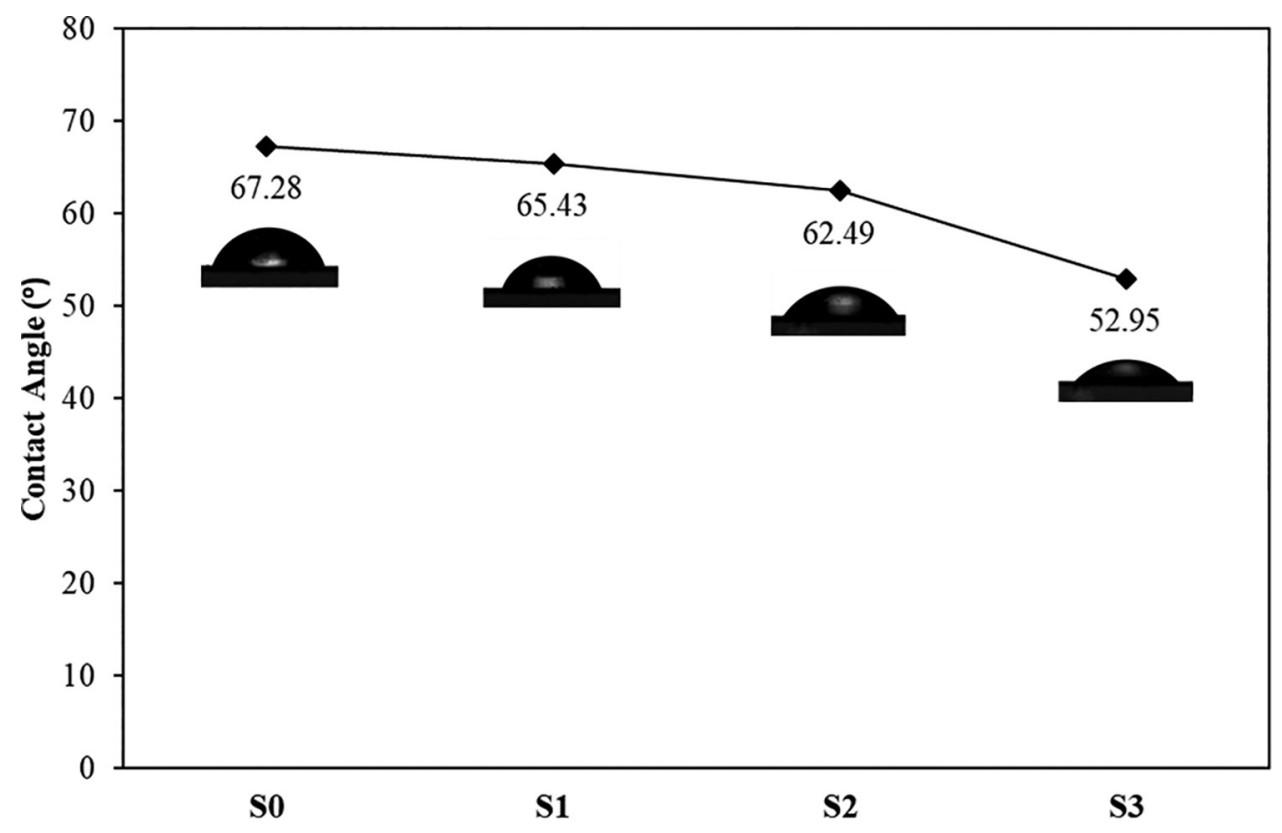

Figure 6: Average contact angle of S0, S1, S2 and S3 membranes.

\subsection{Filtration Performance}

An excellent membrane will provide high solute rejection with high permeability but with low fouling tendency. ${ }^{10}$ Cross-flow filtration process was tested using the as-prepared membranes to filter HA from the feed solution and the results on the membrane filtration performance are shown in Table 2. S0 shows high HA rejection of $94.75 \%$ but significantly low permeability. The pores are small enough to achieve high HA rejection, but it is too small for the water to permeate.

All modified membranes show high HA rejection, i.e., more than $90 \%$ with $\mathrm{S} 3>\mathrm{S} 0>\mathrm{S} 1>\mathrm{S} 2$. In terms of permeability, they show higher flux for both PWF and HA with $\mathrm{S} 1>\mathrm{S} 3>\mathrm{S} 2>\mathrm{S} 0$. The significant increase in fluxes for $\mathrm{S} 1$ is the result of having the biggest pore size thus providing large passage for water to permeate through the membrane. Meanwhile, S2 shows small increment in permeability with respect to membrane $\mathrm{S} 0$ due to a small increase in hydrophilicity as discussed in previous section. On the other hand, the synergistic effect of both MCC and $\mathrm{LiCl}$ significantly improved S3 morphology and hydrophilicity. These improved characteristics of the membrane induced excellent performances to the membrane. 
Table 2: FRR, RFR, membrane fluxes and HA rejection of S0, S1, S2 and S3 membranes.

\begin{tabular}{|c|c|c|c|c|c|c|}
\hline Membrane & $\begin{array}{c}J_{\mathrm{PWF} 1} \\
\left(\mathrm{~kg} \mathrm{~m}^{-2} \mathrm{~h}^{-1}\right)\end{array}$ & $\begin{array}{c}\mathrm{J}_{\mathrm{HA}} \\
\left(\mathrm{kg} \mathrm{m}^{-2} \mathrm{~h}^{-1}\right)\end{array}$ & $\begin{array}{c}J_{\mathrm{PWF} 2} \\
\left(\mathrm{~kg} \mathrm{~m}^{-2} \mathrm{~h}^{-1}\right)\end{array}$ & $\begin{array}{c}\text { FRR } \\
(\%)\end{array}$ & $\begin{array}{c}\text { RFR } \\
(\%)\end{array}$ & $\begin{array}{c}\text { Rejection } \\
(\%)\end{array}$ \\
\hline S0 & $\begin{array}{l}0.5091 \pm \\
0.1330\end{array}$ & $\begin{array}{l}0.2066 \pm \\
0.0534\end{array}$ & $\begin{array}{l}0.0422 \pm \\
0.0196\end{array}$ & 8.29 & 59.42 & 94.75 \\
\hline S1 & $\begin{array}{l}69.2657 \pm \\
2.0449\end{array}$ & $\begin{array}{l}38.6860 \pm \\
0.6620\end{array}$ & $\begin{array}{l}36.7040 \pm \\
0.0857\end{array}$ & 52.99 & 44.15 & 91.19 \\
\hline S2 & $\begin{array}{l}3.1642 \pm \\
0.1013\end{array}$ & $\begin{array}{l}0.8285 \pm \\
0.0817\end{array}$ & $\begin{array}{l}1.1254 \pm \\
0.1283\end{array}$ & 35.57 & 73.82 & 90.89 \\
\hline S3 & $\begin{array}{l}11.2990 \pm \\
0.1506\end{array}$ & $\begin{array}{l}7.4330 \pm \\
0.1081\end{array}$ & $\begin{array}{l}7.3198 \pm \\
0.1377\end{array}$ & 64.78 & 34.22 & 94.91 \\
\hline
\end{tabular}

\subsection{Membranes Fouling Evaluation}

RFR and FRR were calculated using Equations 3 and 4, respectively and the results are shown in Table 2. Generally, low RFR and high FRR are favourable as these values indicate that the membranes have a good antifouling property. ${ }^{11}$ As observed, S3 shows the lowest RFR and the highest FRR value. This indicates that S3 possesses the best antifouling capability, followed by S1 and S2. The reason for the highest FRR and the lowest RFR can be ascribed due to improved hydrophilicity of the membrane surface which signifies that the membrane is less susceptible to fouling as water attracts the membrane surface to form a layer between the membrane and HA, thus fewer adsorption sites for HA are attached.

By taking cognizance of the rejection, permeate flux and fouling performance, it can be concluded that PES MMM incorporated with MCC in the presence of $\mathrm{LiCl}$ (S3) was found to be the best membrane as it possessed the highest antifouling capability and achieved a significant increase in permeate flux with high HA rejection. Perhaps with proper optimisation, the result will further improve. Based on the performance in the current work, it can be concluded that the MCC possesses a great potential additive for the treatment of surface wastewater.

\section{CONCLUSION}

In this work, four PES membranes with different compositions of MCC and $\mathrm{LiCl}$ were prepared via blending and dry-wet phase inversion. Results show that the membrane hydrophilicity and morphology were greatly improved with the presence of both MCC and $\mathrm{LiCl}$. FTIR and CA analysis demonstrated that MCC was successfully deposited on PES membrane with the aid from $\mathrm{LiCl}$, thus improving the hydrophilicity. The best performance was obtained with PES MMM 
incorporated with $\mathrm{MCC}$ in the presence of $\mathrm{LiCl}$. In this case, the PWF and permeate flux were significantly increased from $0.5091 \mathrm{~kg} \mathrm{~m}^{-2} \mathrm{~h}^{-1}$ to $11.2990 \mathrm{~kg} \mathrm{~m}^{-2} \mathrm{~h}^{-1}$, and from $0.2066 \mathrm{~kg} \mathrm{~m}^{-2} \mathrm{~h}^{-1}$ to $7.4330 \mathrm{~kg} \mathrm{~m}^{-2} \mathrm{~h}^{-1}$, respectively whilst maintaining high HA rejection of $94.91 \%$. Furthermore, this membrane possessed the highest antifouling capability in terms of FRR and RFR. It can be concluded that MCC possessed as a great potential additive for the treatment of surface wastewater.

\section{ACKNOWLEDGEMENTS}

The authors acknowledge the financial support provided by Universiti Sains Malaysia under Fundamental Research Grant Scheme (FRGS) grant (grant no. 203.PJKIMIA.6071355).

\section{REFERENCES}

1. Zularisam, A. W., Ismail, A. F. \& Salim, R. (2006). Behaviours of natural organic matter in membrane filtration for surface water treatment: A review. Desalin., 194(1-3), 211-231, https://doi.org/10.1016/j.desal.2005.10.030.

2. Schäfer, A. et al. (2000). Microfiltration of colloids and natural organic matter. J. Membr. Sci., 171(2), 151-172, https://doi.org/10.1016/S0376-7388(99)00286-0.

3. Zhang, L. et al. (2019). A loose NF membrane by grafting $\mathrm{TiO}_{2}-\mathrm{HMDI}$ nanoparticles on PES/ $\beta-C D$ substrate for dye/salt separation. Sep. Purif. Technol., 218, 8-19, https://doi.org/10.1016/j.seppur.2019.02.018.

4. Ahmad, A. L. et al. (2019). PES/PVP/TiO 2 mixed matrix hollow fiber membrane with antifouling properties for humic acid removal. J. Water Process. Eng., 31, https://doi.org/10.1016/j.jwpe.2019.100827.

5. Safarpour, M., Vatanpour, V. \& Khataee, A. (2015). Preparation and characterization of graphene oxide $/ \mathrm{TiO}_{2}$ blended pes nanofiltration membrane with improved antifouling and separation performance. Desalin., 393, 65-78, https://doi.org/10.1016/j.desal.2015.07.003.

6. Zhang, Y. et al. (2016). High alkaline tolerant electrolyte membrane with improved conductivity and mechanical strength via lithium chloride/dimethylacetamide dissolved microcrystalline cellulose for Zn-air batteries. Electrochim. Acta, 220, 635-642, https://doi.org/10.1016/j.electacta.2016.10.103.

7. Zhang, C. et al. (2014). Dissolution mechanism of cellulose in N,Ndimethylacetamide/lithium chloride: Revisiting through molecular interactions. J. Phys. Chem. B, 118(31), 9507-9514, https://doi.org/10.1021/jp506013c.

8. Mohd Shafie, Z. M. H. \& Ahmad, A. L. (2018). Juxtaposition of PES based hollow fiber membrane: Antifouling and antibacterial potential of licl mediated PVA-ZnO blend. J. Ind. Eng. Chem., 62, 273-283, https://doi.org/10.1016/j.jiec.2018.01.005.

9. Jia, N. et al. (2011). Synthesis and characterization of cellulose-silica composite fiber in ethanol/water mixed solvents. Biores., 6(2), 1186-1195. 
10. Chollom, M. N. \& Rathilal, S. (2018). Fouling and cleaning in osmotically driven membranes. In Du, H. et al. (Eds.), Osmotically driven membrane processes: Approach, development and current status. London: IntechOpen, 179-205.

11. Otitoju, T. A., Ooi, B. S. \& Ahmad, A. L. (2019). Synthesis of 3-aminopropyltriethoxysilane-silica modified polyethersulfone hollow fiber membrane for oil-in-water emulsion separation. React. Funct. Polym., 136, 107121, https://doi.org/10.1016/j.reactfunctpolym.2018.12.018. 